\title{
BUCCAL MUCOSAL GRAFT URETHROPLASTY AS PRIMARY REPAIR HAS SIGNIFICANTLY BETTER OUTCOME THAN AFTER FAILED DVIU CASES- A CLINICAL TRIAL
}

\author{
HASINA SADIA KHAN ${ }^{1}$, AKM ANWARUL ISLAM ${ }^{1}$, AKM KHURSHIDUL ALAM ${ }^{1}$, MOHAMMAD SALAHUDDIN \\ FARUQUE ${ }^{1}$, ISMAT JAHAN ${ }^{2}$, SAYEM HOSSAIN ${ }^{1}$, MOHAMMAD FAISAL ISLAM ${ }^{3}$ \\ ${ }^{1}$ Department of Urology, Bangabandhu Sheikh Mujib Medical University, Dhaka, ${ }^{2}$ Department of Neonatology, \\ Bangabandhu Sheikh Mujib Medical University, Dhaka, ${ }^{3}$ Department of Urology, National Institute of Kidney Diseases and \\ Urology, Dhaka.
}

\begin{abstract}
Introduction: Direct Visual Internal Urethrotomy (DVIU) is the most commonly used technique for short segment bulbar urethral stricture till date. But it has a high failure and recurrence rate. On the other hand, urethroplasty is regarded as the gold standard treatment for urethral stricture. Moreover, for bulbar urethral stricture, usually more than $3 \mathrm{~cm}$ stricture are treated with substitution urethroplasty. Current practice for short segment bulbar urethral stricture is multiple sessions of DVIU and then buccal mucosal graft (BMG) urethroplasty if they fail. But repeated DVIU make the stricture segment longer and more fibrotic. Considering the morbidities following repeated DVIU, this prospective clinical trial has been designed to compare the outcome of BMG urethroplasty after failed urethrotomy versus primary repair.
\end{abstract}

Objective: To determine stricture recurrence, PVR and flow of urine in between primary $B M G$ urethroplasty group and after failed DVIU group.

Patients and Methods: The present study was conducted in the department of Urology, BSMMU between July'15 - February'17. Patients of short segment bulbar urethral stricture between 1.5- $3 \mathrm{~cm}$ without any previous DVIU were enrolled as study group $(n=22)$ and patients with history of failed DVIU were included as control group $(n=22)$. All the patients were followed upto 12 months after BMG urethroplasty and recurrence of stricture (by RGU and $M C U), P V R$ and maximum urine flow rate (Qmax) in between two groups were compared.

Results: The stricture recurrence rate was found significantly higher in control group than in the study group ( $p=0.042$ ). The study group showed highly significant (0.000) decrease in post-operative $P V R$ and significant (0.009) increase in post operative maximum urine flow rate than the control group as was assumed in the hypothesis.

Conclusion: The present study propose that BMG urethroplasty as primary repair for bulbar urethral stricture within a length of $1.5-3 \mathrm{~cm}$ in younger age group (upto 45 years) is very effective than BMG urethroplasty after failed DVIU cases. But long term multicentric trial is needed to further comment.

Keywords: Bulbar urethral stricture, DVIU, BMG urethoplasty, Stricture recurrance.

Bangladesh J. Urol. 2018; 21(1): 3-7

Correspondences: Dr. Hasina Sadia Khan, Department of Urology, Bangabandhu Sheikh Mujib Medical University, Dhaka, 


\section{Introduction}

Urethral stricture disease is one of the commonest problem in urological practice ${ }^{1}$. The bulbar urethral stricture burdens heavier among the other locations ${ }^{2}$. The treatment options vary according to the length of stricture, DVIU for $<1 \mathrm{~cm}$, end to end anastomosis for $1-2 \mathrm{~cm}$, augmented roof strip anastomosis for $2-3 \mathrm{~cm}$ stricture and stricture longer than $3 \mathrm{~cm}$ are treated by using substitution urethroplasty ${ }^{3}$. The problem regarding all the treatment options is recurrence of stricture. However the recurrence rate after DVIU is $92 \%$ and repeated DVIU exacerbates scar formation which adds to stricture length \& predisposes to a more difficult definitive open repair ${ }^{2}$. On the otherhand, Buccal mucosal graft is an ideal urethral substitute from 1941 4 . Standard bulbar urethroplasty using buccal mucosal graft has a lifetime success rate of $92 \%{ }^{5}$. Now-a-days, some authors prefer BMG urethroplasty for short segment stricture instead of anastomotic urethroplasty considering the higher complication rate after anastomotic urethroplasty ${ }^{6}$.

So, considering the recurrence rate and all possibilities of further surgery be difficult after DVIU, the aim of the study was to assess if BMG urethroplasty can be approached as a primary modality of treatment for short segment bulbar urethral stricture .

\section{Materials and Method}

The present study was conducted in the department of Urology, BSMMU between July'15 - February'17. All patients of short segment bulbar urethral stricture ranging $1.5-3 \mathrm{~cm}$ presenting to urology department BSMMU for BMG urethroplasty from july'15- february' 16 were the study population. Patients aging below 18 years and above 55 years were excluded from the study. No complex urethral stricture ( BXO, GU malignancy or previous failed urethroplasty), long segment stricture or complete luminal occlusion by stricture were included. Patients with BEP (gland size $>40 \mathrm{gm}$ ) and neuropathic bladder were not included in the study. Patient without any previous DVIU were purposefully enrolled as study group(group- $A, n=22$ ) and patients with history of failed DVIU were included as control group(group- $B, n=22$ ).
All the patients were followed upto 12 months after BMG urethroplasty (upto february'17) and recurrence of stricture (by RGU and $M C U$ ), post void residual urine (PVR) and maximum urine flow rate (Qmax) in between two groups were compared. Chi-squared test was performed for qualitative variable and for quantitative variable students T-test was performed. SPSS version 20 was used for statistical analysis.

\section{Result}

The patients included in the study were in the age range of 18-55 years. Most of the patients were between 3040 years of age. About $50 \%$ in group-A and $40.9 \%$ in group-B were in the age group of 30-40 years. In groupA $7(31.81 \%)$ and in group-B $9(40.9 \%)$ patients were in the age group of $40-55$ years age group. In both groups only $4(18.18 \%)$ patients were in $18-30$ years age group. Mean $( \pm S D)$ age of group-A was $37.09( \pm 7.495)$ and groupB was 38.32( \pm 8.57$)$. Difference between age of two were not statistically significant $(p=0.271)$.

The mean $( \pm S D)$ duration of symptoms of group-A was $27.55( \pm 12.82)$ months and group-B was $28( \pm 13.02)$ months. The mean $( \pm S D)$ length of stricture of study group was $2.482( \pm 1.09) \mathrm{cm}$. and control group was $2.75( \pm 0.29) \mathrm{cm}$. The mean $( \pm S D)$ pre-operative PVR of group-A was $92.18( \pm 27.91) \mathrm{ml}$. and group-B was $88.73( \pm 22.97) \mathrm{ml}$. The mean $( \pm S D)$ pre-operative maximum flow rate of urine (Q-max) of group-A was $6.614( \pm 1.84) \mathrm{ml} / \mathrm{s}$. and group-B was $6.991( \pm 1.66) \mathrm{ml} / \mathrm{s}$.

So, there was no statistically significant difference between the study and the control group in terms of duration of symptoms $(p=0.840)$, length of stricture $(p=0.05)$, pre-operative PVR $(p=0.674)$ pre-operative maximum flow rate of urine ( $Q-\max )(p=0.944)$. (Table- 1$)$

There was decrease in postoperative PVR in the study group. But the mean decrease in post operative PVR was noted higher in the study group than in control group. And the amount of decrease was statistically highly significant $(p=0.002)$. The mean increase in maximum urine flow rate (Qmax) after BMG urethroplasty in the study group $(15.582 \pm 4.4997 \mathrm{ml} / \mathrm{s})$ was noted significantly higher $(p=0.009)$ than in the control group (13.968 $\pm 6.5285 \mathrm{ml} / \mathrm{s})$. (Table-1).

Table-I

\begin{tabular}{lccc}
\hline Variables & Group A & Group B & P-value \\
& Mean \pm SD & mean \pm SD & \\
\hline Duration of symptoms & $27.55 \pm 12.82$ & $28 \pm 13.02$ & 0.840 \\
Length of stricture & $2.482+1.09$ & $2.759 \pm 0.29$ & 0.05 \\
Preoperative PVR & $92.18 \pm 27.91$ & $88.73 \pm 22.97$ & 0.674 \\
Pre operative Q-mas & $6.614 \pm 1.84$ & $6.991 \pm 1 . G G$ & 0.944 \\
Post-Operative PVR & $14 \pm 27.431$ & $41.86 \pm 41.574$ & 0.000 \\
Post-operative Q-max & $15.58 \pm 24.4997$ & $13.963 \pm 6-5285$ & 0.009 \\
\hline
\end{tabular}


The total stricture recurrence was $13(29.54 \%)$.It was noted significantly $(p=0.042)$ higher control group $(40.91 \%)$ than in study group $(13.64 \%)$.(Table-2) Interestingly, there was significant $(p=0.007)$ increase in stricture recurrence when BMG urethroplasty was done over the age of 45 years. There was increase in tendency in stricture recurrence among the patients who presented with more than 24 months of symptoms $(31.82 \%)$ rather than those who presented with symptom duration less than 24 months $(22.73 \%)$. But it was not statistically significant $(p=0.322)$. Among the 13 recurrences, 9 of them had history of previous urethral instrumentation (DVIU and dilatation) e"3 times. So, recurrence rate is significantly high $(p=0.001)$ when there was increase in the number of instrumentation (e" 3 times). The increase in recurrence rate of stricture was noted in patients who used to do $\mathrm{CISC}(66.67 \%)$ rather than patients who didn't do CISC(10.34\%). The difference was statistically significant $(p=0.000)$. (Table-3)

Table-II

\begin{tabular}{lccc}
\hline & $\begin{array}{c}\text { Group-A } \\
\mathrm{N}(\%)\end{array}$ & $\begin{array}{c}\text { Group-B } \\
\mathrm{N}(\%)\end{array}$ & $\begin{array}{c}\mathrm{P}- \\
\text { value }\end{array}$ \\
\hline Recurrence of & $4(13.64 \%)$ & $9(40.91 \%)$ & 0.042 \\
stricture & & & \\
\hline
\end{tabular}

Table-III

\begin{tabular}{llr}
\hline & & P-value \\
\hline Relation of stricture & Age category & 0.000 \\
recurrence with & $(45-55$ yrs $)$ & \\
variables & Duration of symptoms & 0.322 \\
& No of previous & 0.001 \\
& instrumentation & \\
& Previous history of CISC & 0.000 \\
\hline
\end{tabular}

\section{Discussion}

Short segment bulbar urethral stricture burdens almost $10 \%$ of the day case surgeries in tertiary health centers in Bangladesh ${ }^{7}$. Moreover, the majority of them present with recurrence of stricture and necessitates more than single intervention and regular CISC. Urethral reconstruction after previous manipulation is limited by compromised vascular supply and fibrosis ${ }^{8}$. Furthermore, though there is no obvious cost analysis in this country, the total cost per patient in whom stricture was managed only endoscopically was $£ 6,116$, in comparison to the total cost per patient of persuing a single urethrotomy followed by urethroplasty for stricture recurrence was $£ 5,866^{9}$. So, it is also a burning clinical and economic issue for this country.

In this context, this study analyzed the recurrence rate after BMG urethroplasty between primary cases as well as after failed DVIU cases. The mean age of the study group was $37.09( \pm 7.495)$ and that of control group was $38.32( \pm 8.57)$ and there was no statistically significant $(p=0.271)$ difference between the study and control groups. In 2001, a similar study was conducted in Italy on 93 males having a almost identical mean age $(39)^{10}$.

In the present study, the two groups showed no statistically significant difference in terms of duration of symptoms, length of stricture, pre-operative PVR and pre-operative urine flow rate(Qmax). This added an advantageous state to work on two groups those were almost homogeneous except the number of previous instrumentation, the affect of which was evaluated.

The stricture recurrence rate was found significantly low $(p=0.042)$ in cases of BMG urethroplasty as primary repair rather than in BMG urethroplasty after failed DVIU cases during this short study period. Ziprin et al stated the similar findings that urethroplasty is compromised after repeat urethrotomy ${ }^{11}$. Roehrborn and McConnell also found a doubling in the failure rate for those with multiple dilatations than to those without any prior manipulation ${ }^{12}$. In contrast to a similar study at itally, primary urethroplasty had a final success rate of $85 \%$ and urethroplasty after failed urethrotomy was $87 \%$, which was not statistically significant ${ }^{10}$.

In this present study, some factors were clearly identified contributing to the failure of BMG urethroplasty, those were age, number of previous instrumentations and history of CISC. Other studies also suggested those factors to be important issues of failure ${ }^{10}$. In this present study, recurrence was observed more in patients who underwent 3 or more previous urethral instrumentations and the difference from those who underwent less than 3 manipulations is statistically significant $(p=0.001)$. Berger et al noted that the frequency of dilatation before surgical repair was the single most important factor for determining success versus failure ${ }^{13}$. Rosette et al reported the largest proportion of recurrence was noted among those who underwent more than 3 urethrotomies during a short interval ${ }^{14}$.

The current study found, history of doing CISC prior to BMG urethroplasty to be a statistically significant 
determining factor $(p=0.000)$ of stricture recurrence. The cause is established one from different studies. The microtrauma following CISC exacerbating spongiofibrosis ultimately results in failure after BMG urethroplasty ${ }^{15}$.

In the recent study, recurrence rate was much higher in age group 45 and above than below 45 years and that was statistically highly significant $(0.000)$. This may be due to the fact of increasing no of ancillary per urethral procedures in older population. Another study also suggested urethroplasty to be less effective in patients older than 55 years of age and demonstrated number of per urethral surgery to be an issue for the failure ${ }^{9}$. The relationship of recurrence with the duration of symptoms was not established in the present study.

On comparing pre and post-operative PVR between the two groups of this study, there was more decrease in post operative PVR in the study group rather than in control group and the change was highly statistically significant. Moreover, there is significant $(p=0.009)$ improvement in post-operative urine flow rate ( $Q$ max) in the study group. This may be one of the reflection of more spongiofibrosis in case of repeated urethral instrumentation.

After reviewing the result of this study, it became evident that the result of BMG urethroplasty is a golden option for short segment $(1.5-3 \mathrm{~cm})$ bulbar urethral stricture in young patients who underwent less than 3 urethral instrumentations. There are several studies in support of this remark. Wright et al. determined, using decision analysis, the cost-effectiveness of different management strategies for short bulbar urethral stricture is to reserve urethroplasty in whom a single endoscopic attempt has failed ${ }^{16}$. Rourke and Jordan suggested that treatment for a $2 \mathrm{~cm}$ bulbar urethral stricture with primary open urethroplasty is less costly than endoscopic treatment ${ }^{17}$. On another verse, urethroplasty should be considered primary therapy in younger individuals with strictures following straddle injury or as second line in whom one attempt at endoscopic management failed ${ }^{9}$.

The present study showed a high rate recurrence of stricture in a short follow-up period. This is thought to be due to underestimation of stricture length as the luminal size adjacent to the stricture segment did not correlate with the extent of fibrotic area. A former study in United Kingdom already established this factor to be a cause of failure ${ }^{8}$. Another reason of this, presumed to be graft sacculation for ventral placement of graft and ultimate luminal narrowing. This is a common complication after ventral graft placement ${ }^{18}$.
This present study was a prospective one and done in between two almost homogenous groups. On the other hand, most of the previous studies were retrospective. Moreover, this type of study was not published in Bangladesh till to date.

The aim of the study was to compare recurrence by RGU and MCU, PVR and urine flow rate between the two groups. Hence cause of stricture, erectile dysfunction and oral morbidity following buccal mucosa harvest were not documented. But all this adjuncts might have ornamented the study to a great value. As the length of stricture included in this study is very short so comparison of recurrence in terms of length of stricture was avoided. The short follow-up revealed a weak dimension of the study.

So, a long term, multicentric trial with additional variables is recommended for a definite conclusion to be made on the treatment strategy for short segment bulbar urethral stricture which have a huge clinical impact on further management options.

\section{References}

1. Brandes, S. B., Smith, J., Virgo, K. and Johnson, F. E.: Adult t anterior urethral strictures: a national practice patterns survey. J Urol, suppl 2001; 165: 13, abstract 53.

2. Peterson AC, Webster GD: Management of urethral stricture disease: developing options for surgical intervention. BJU Int 2004; 94: 971-6.

3. Barbagli G, Palminteri E, Lazzeri M, Guazzoni G: Anterior urethral strictures. BJU Int 2003; 92: 497505.

4. Humby G. A one-stage operation for hypospadius repair. Br J Surg 1941;29:84-92.

5. Bhargava S, Chapple CR. Buccal mucosal urethroplasty: Is it the new gold standard? BJU Int 2004;93:1191-3.

6. Zimmerman W B, Santucci R A. Buccal mucosa urethroplasty for adult urethral strictures. Indian $\mathrm{J}$ Urol 2011; 27(3): 364-370.

7. Hospital records, BSMMU, 2016.

8. Joseph J V, Andrich D E, Leach C J, Mundy A R. Urethroplasty for refractory anterior urethral stricture. The journal of Urology 2003;167:127-129.

9. Greenwell TJ, Castle C, Andrich DE, MacDonald JT, Nicol DL, Mundy AR: Repeat urethrotomy and dilation for the treatment of urethral stricture are 
neither clinically effective nor cost-effective. J Urol 2004; 172: 275-7

10. Barbagli G, Palminteri E, Lazzeri M, Guazzoni G, Turini D.Long term outcome of urethroplasty after failed urethroplasty versus primary repair. The journal of urology 2010;183:1859-62.

11. Ziprin, P., Wheeler, J., Davies, G. et al: The longterm follow-up of the urethroplasty for non-traumatic urethral strictures. J Urol suppl. 199; 155.

12. Roehrborn, C. G. and McConnell, J. D.: Analysis of factors contributing to success or failure of 1stage urethroplasty for urethral stricture disease. J Urol 1994; 151: 869.

13. de la Rosette, J. J., de Vries, J. D., Lock, M. T. et al: Urethroplasty using the pedicled island flap technique in complicated urethral strictures. J Urol 1991; 146: 40.
14. Berger, B., Sykes, Z. and Freedman, M.: Patch graft urethroplasty for urethral stricture disease. J Urol 1976; 115: 681.

15. Kurt A, McCammon, Jack M, Zuckerman, Gerald $\mathrm{H}$, Jordan. Surgery of the Penis and Urethra. In: Wein A J, Kavoussi L R, Partin A W, Peters C A, eds. Campbell- Walsh Urology. International edition, Elsevier.

16. Wright $\mathrm{JL}$, Wessells $\mathrm{H}$, Nathens $A B$, Hollingworth $\mathrm{W}$ : What is the most cost-effective treatment for 1 to 2-cm bulbar urethral strictures: societal approach using decision analysis. Urology 2006; 67: 88993.

17. Rourke KF, Jordan GH: Primary urethral reconstruction: the cost minimized approach to the bulbous urethral stricture. J Urol 2005; 173: 1206-10.

18. Barbagli G, Selli C, Tosto A, Palminteri E. Dorsal free graft urethroplasty. J Urol 1996;155:123-126. 